\title{
What can and cannot be achieved by advertising
}

\author{
BY ANN BURDUS* \\ Health Education Authority, Hamilton House, Mabledon Place, London WC1H 9TX
}

One of the names associated with advertising which is known outside the business, in addition to Saatchi and Saatchi, is David Ogilvy. He is a legendary figure who built up an agency of world renown which has only recently been bought by WPP Group plc. It is too early to say whether the new ownership will change much but we do know that the old agency was a remarkable one that bore the stamp of the man who created it, with his beliefs about how advertising works.

If you read his books (Ogilvy, 1963, 1978) you will find them entertaining and didactic as well as self-contradictory. Although he had, and has, strong views about how advertising works, David Ogilvy is still interested to learn more. so a few years ago he decided to set up a foundation to study how advertising works. He and his board looked for people to head the foundation and the headhunters they cmployed were surprised to find that the same names kept being recommended; it was a small list and the people on it were all over 40 years of age.

Few young people in the advertising industry in the UK today spend much time on the theory of how advertising works. They concentrate their intellectual effort on the precise positioning of the individual product: who do they expect to buy it, what is the most economical way to reach these people, and what message is likely to persuade them to buy. All these things are important, but over recent years the actual mechanism of how advertising works. how the persuasive mechanism works, has been neglected. This was not always so. In the late 1960 s there was a need for more effective advertising. more reasonable and, if you like, more scientific or precise advertising.

You will find quite a range of American books written at that time by people who were confident that all you had to do was to identify a unique selling proposition, communicate it to people so that they noticed it and remembered it, and you would successfully sell the product. If I asked you to tell me the advertising slogans that came most readily to mind and then ask how many of you have ever purchased those particular products, the fallacy of this position is evident.

Some theories were a little more complex and were given names like Awareness, Information, Desire and Action (AIDA) and Defining Advertising Goals for Measured Advertising Results (DAGMAR), but basically they showed little subtlety in their appraisal of how people receive and act on information (Broadbent, 1980).

When I joined McCann Erikson for example in 1971, I was asked to work on how we could be accountable to clients for the advertising we produced; how could we measure and demonstrate its effectiveness?

This desire to demonstrate the value for money of what we were doing came from the USA, and with the internationalization of package-goods advertising there was a move to introduce the same pretesting and post-testing techniques here as were used there.

The British, not for the first nor last time, rebelled. We found the measurement systems that were suggested likely to penalize the sort of advertising we were producing

*Present address: Olympia \& York Canary Wharf Ltd. 10 Great George Strect. London SWIP 3AE. 
and we, therefore, challenged the intellectual basis of the measurements. We claimed that they were based on a false premiss of the advertising process.

These were heady days when thoughtful people in the UK challenged the models of the advertising process which were implicit in the measurement systems employed in the American advertising industry. We challenged the simplistic models behind the measurement processes. Broadly speaking the measurement systems said that advertisers should make people pay attention and then communicate information which would induce a change of attitudes and, thus, a change in behaviour.

Not only is this an appallingly simplistic view of the way advertising works; the related measurement systems were even more simplistic. Advertisements were chosen because people could remember having seen them and could recall the message that was contained in them. No matter how hard we argued that recall is not a measure of attention or communication, this measurement system stuck and is still to be found amongst some of the major international package-goods companies today. Challenged by their success, those of us who were appalled by the weakness of their intellectual reasoning could only say that the advertising industry was so weak in theory at the time that any systematic approach was bound to improve performance. The key papers which encapsulate the debate were given by Dr. Timothy Joyce at two seminars organized by the European Society for Opinion and Marketing Research (ESOMAR) in 1967 and 1971 (Joyce, 1967, 1971).

The importance of this debate was not the conclusions but the fact that it made people think. Much more elaborate models of the communication process were developed, like those of Fishbein (1971). However, out of this process probably the single most important idea to emerge was that advertising does not work in one way; there is not one model of the advertising process but many. Even the goals and targets of advertising can be different, and the role that advertising plays in the total communication process can vary quite considerably from one occasion to another. Additionally, this examination of the advertising process caused us to consider the psychological process of communication and to realize that communication is not a one-way process. Too often people think of advertising as a message scratched on a slate, a slogan written on a wall. What we are really talking about is one person trying to insert an idea into the belief system of another. We are talking about communicating with someone who already has a complex set of beliefs, attitudes and ideas.

I was moved recently when one of my ex-colleagues sent me a copy of a study she had completed on the attitudes and ideas of young people round the world. This was the third of these studies and she and I had been jointly involved in the second. In this most recent report she quoted my words from the second: 'Communication is a two-way process involving both the person who is communicating and the person who will receive and interpret the message. It is impossible to create effective advertising without an understanding of the people with whom we are trying to communicate'.

At its simplest level you can interpret that to mean you cannot communicate with someone unless you know, in the vernacular, 'where he is coming from'. If you get the symbolism wrong you will alienate him or he will edit out what you are saying as irrelevant to him. I believe that many of my colleagues in the advertising business see this as a conscious process. My real meaning was much deeper. I truly believe that unless you communicate in the right way you impinge neither consciously nor unconsciously on the person with whom you are trying to communicate. 
We pay insufficient attention to the selection process which must go on in the human brain. We are bombarded with sensations through all our senses at all times, so an editing process for relevance to our needs and values must take place. I will not discuss the complex psychological mechanism which will allow an individual to edit-in or edit-out a message at a particular time. We all have personal experiences of our olfactory senses being heightened by need. I think most of us with a little thought can identify occasions when we have edited-out messages which are irrelevant for us. On the positive side we know occasions when signals have told us that this message is for me, it is in my language. Perhaps the easiest and simplest message-carrier of this kind in the modern world is music which quickly indicates the audience for whom the message is intended.

This simple concept of the selection of messages presents a special and interesting challenge to those concerned with changing eating patterns or increasing knowledge about nutrition. If we set about the task in the wrong way, using the wrong signals, there is every likelihood that our messages will be heard only by those who are actually interested in nutrition. I would not attempt to solve such a complex problem but I would suggest that the right vehicle for the message is the key. When Marshall McLuhan said 'the medium is the message' (McLuhan, 1964), he was giving us one of the most profound thoughts about communications of his generation.

One thing we did not do in the 1960 s and 70 s was to challenge the concept of mass communication. Nor do I think many practitioners today examine when it is proper to use mass communication and when this is inappropriate. To some extent they have moved towards it because they are accepting the concept of niche marketing. There is a growing realization that with advances in technology and with deregulation and fragmentation in the media. it is possible, as well as desirable. to address quite specific subsectors of the population.

Do not underestimate how revolutionary this is. We have all been brought up in a time when mass has meant good. Mass education, mass welfare, mass production, mass media. We know that the benefits of mass production are a mass market, mass demand and, thus, a lowering of prices which fuels the system. We know that the larger the audience for a medium, the more money attracted through advertising revenues, the more money is available to produce better programmes, the larger the audiences attracted. These are the concepts with which we have grown up so we must be forgiven if it takes us a little time to realize that what we know would be more effective, more precise if not individual targeting, is now more possible than ever it was before.

You have asked me to share with you the theory and concepts of mass communication which might help in advertising in relation to nutrition at a time when the advertising industry is facing the challenge of new opportunities for more efficient communications, which are a move away from true mass communications as we know it.

To return to the heady days of the 1960 s when we rejected recall of advertising as a measure of its effectiveness and also the implicit model of communications which lay behind such a measure, many of us said that we were not trying to lodge slogans in people's heads, but get them to change their attitudes. If they changed their attitudes then behaviour change would follow. Some were, therefore, dumbfounded to discover that in certain cases the pattern was communication, behaviour change, attitude change, rather than attitudes preceding behaviour. Pcople have followed the example of others or experimented without believing what you say. This is based on sound sociological theory. 
We also began to recognize that the ideas and methods which were appropriate for package goods were perhaps less appropriate for some of the other areas where advertising was now being applied. Although advertising has always been used for a wide range of purposes from politics and propaganda to services and straightforward information as well as package goods selling, nevertheless it was the latter with the enormous sums of money involved. that became associated with the industry as it grew in sophistication in the middle of the present century.

If you look at mass media today, however, you will see that the expenditure on package goods advertising has declined as a proportion of the total for several years and that there has been a steady increase in advertising of services, and what we could call issue or advocacy advertising.

It is completely wrong to try to take the methods for advertising package goods and to assume that they will work in social issue or advocacy advertising. At the simplest level we can say that packaged-goods manufacturers are pushing on an open door. To a greater or lesser extent people are ready to buy these products. Perhaps the most extreme advertising problem I have ever faced at the opposite end of the spectrum is our Health Education Authority advertising in relation to AIDS. How do you persuade healthy young people to either limit their sexual activity or wear a condom? I am by no means defeated but we have to recognize that neither moral pressure nor fear of illness and death has successfully modified sexual behaviour over the centuries. We have quite a battle to persuade people to do something they do not want to do.

Although I have said on several occasions that AIDS is the most challenging communications problem I have ever faced, this is largely because of the importance of persuading people to change their behaviour, the intellectual challenge of the situation and the social structure within which we operate.

The nutritional communication problem is complex. AIDS may be more complex in some other ways but the messages we wish to convey in relation to nutrition are not simple and the key role of advertising may be to get the individual to think and then assess his behaviour against what is recommended in other sources of information.

However, we must be consistent, not only in what we say but in the symbols we use to say it.

The Esso tiger has been around for 20 years and he is used to flag the message; if people want detailed information they look elsewhere. The Lloyds Bank horse which is slightly younger does not try to sell you the details of a loan or a mortgage, he is used to encourage you to look elsewhere for further information, but the symbol is recognized to have enormous value which would not lightly be disregarded.

Nutrition is almost as challenging as AIDS but in a totally different way. Although we would like to see many people change their bchaviour. they start from many different points and there is no simple message to put across. Additionally we have to devise a meaningful language which is useful to the public, even if it is offensive to the scientists. Further, even if people want to change their behaviour it is not easy for them to do so because the links in the chain are not there; there is no one simple description of the product through the chain from producer, processor, retailer, preparer to consumer. Most fundamentally we have to recognize that there is not one audience and that we have to simplify our message; we must also recognize the limitations of advertising which is not nearly as powerful as people outside the industry believe. If we think of the scepticism with which the general public have reacted to some extremely powerful 
propaganda machines over the years, this will be evident. Advertising reaches its maximum effectiveness when it coincides with a social trend and when it is complemented by other activity. Probably some of the most moving, applauded, prize-winning advertising that has been created was that intended to encourage us to wear seatbelts, yet in the end government lost paticnce and legislated instead of making this a voluntary activity.

It is a well-known adage that law which cannot be enforced is bad law, and had not public opinion already been changing towards seatbelts then the laws would have been more difficult to introduce and enforce.

I am not sure, however, that it would be true to write off that particular advertising campaign as a failure. The combination between what is mandatory and what is voluntary is complex. I suspect that at present we may be facing a real social change in relation to drink and driving. People will still drink and drive and there will be horrific results from time to time. Personal observation would suggest that it is increasingly socially unacceptable to drink and drive. It is my belief without proof, that legislation and advertising are important in leading towards this change in attitudes and behaviour.

In this I am again implying that advertising has many roles. One important role is to create the background against which a sale can take place. There is a well-known advertisement in the business which shows a rather fearsome businessman behind his desk saying 'well young man I don't know you, I don't know your product, I don't know your firm. I don't know your reputation - now what was it you wanted to sell me?'. The implication being that advertising can create the background against which the sale is made.

This introduces us also to the idea of advertising as an endorsement. One of the powerful arguments against tobacco advertising is that although the advertisements may or may not encourage people to smoke, as long as they appear they suggest that society does not totally condemn the use of tobacco.

It is sometimes difficult for people from other disciplines to accept that the general public have a positive attitude to advertising and do not feel antagonistic towards advertisements. There is such a deep antagonism among some academics and other intellectuals that they do not notice that as far as the general public are concerned. advertising messages have a specific credibility; when an advertiser says something. they know the advertiser has paid good money to communicate his message and that the media would not carry it unless it was more or less true. If the government advertise on a particular matter then it must be serious. We might ask whether the massive privatization' advertising may have damaged this last point.

Some people in the public sector shy away from advertising with distaste. They do not recognize that this is a minority response. Over $80 \%$ of the general public say they approve of advertising (Advertising Association, 1988). The number giving this response has increased steadily over the years. Only $8 \%$ dislike newspaper and magazine advertising, only $14 \% \mathrm{TV}$ advertising and only $10 \%$ posters. Advertising is part of people's lives and one of the many ways they receive communications which they evaluate, accept or reject. Advertising is at its most powerful when it is capitalizing on a trend which is already there and which is reflected in society as a whole. When I began working on the challenge of AIDS I talked to some experts in public issue advertising in the United States and they said 'get people to talk about it, get it to be a matter of conversation, give people permission to discuss AIDS and HIV'; they were encouraging me to use advertising to facilitate social communication as an agent of change. 
One of the many complex roles of advertising which is often underestimated is that people use the information to justify behaviour change. This was first noticed in connection with motor car advertising when a researcher found more people read car advertisements in detail after they had bought a car than before; they needed the information to justify the purchase, but in passing it on became a medium for the messages themselves.

I hope what I have been saying has indicated that there are no easy answers but that effective communication is a challenging problem.

This may be an appropriate place to point out that advertising can and does change people's eating patterns, even if it does not change their ideas about nutrition.

When I first began studying this problem in $1977 \mathrm{I}$ discovered an analysis that half the print advertising in magazines in the USA for food products said something about what the product would do for you or the nutritional value of the product, e.g. bran and fibre contents, low fat, polyunsaturated fats and low-cholesterol products, low energy, low salt, no added sugar. Now they are demonstrating that their products have natural calcium which is implicitly good for you.

Interestingly at the same time in many Western countries we saw a sharp change in the advertising strategy of many manufacturers of food products. As well as telling us our families would love us more if we gave them this delicious product, they pointed out that it had no additives or artificial flavourings (France), no harmful additives (Belgium), no dilutions of the necessary vitamins (UK) and so on. You should note that some of these campaigns worked. Fats, brown bread, milk, being some of the cases in point and the Mighty White Loaf being the latest success story.

There is hope! People can be persuaded to change what they eat for the good! How do we learn from these examples? Do not be mistaken, the commercial firms who have communicated information to sell products which have helped people change their eating habits have done so for commercial reasons. They have succeeded because they identified a growing interest in nutrition in the population and themselves fuelled that interest; they succeeded because they pay close attention to the changing attitudes and needs of the people to whom they are selling.

I have worked in and around the advertising business for over 20 years and in and out of the public sector for a rather shorter period. Frankly I would say that part of the success of the best practitioners in advertising is that they have a greater respect for the person with whom they are communicating than some of the people I have met in the public sector, and I assure you that it is extremely difficult to understand someone enough to communicate with them effectively unless you respect them.

Advertising is often criticized for what it does not do. It does not, by and large, preach new stereotypes for women partly because that is not its job and partly because the advertiser knows that the stereotypes communicate and that people are content with these stereotypes.

If you start from the position that you know better and you are going to teach the masses something for their own good, you will get nowhere. If you start from the position that you are dealing with a complex human being who has a lot of beliefs, ideas and ideals as well as social pressures and conventions and that you want to add to or modify some of these ideas by using what is already there, you may have some hope of success.

I hope I have indicated that advertising is most efficient at communicating information (rather than changing behaviour) and that it does this best when it is precisely targeted 
towards people whom the advertiser understands and respects. It is most effective when it can indicate precise action which will lead to a desired personal benefit (do not be too superior, if being beautiful is a stronger motive than living longer, use it!). If what you want to say is too far from the person's current set of beliefs then he will either reject or distort what you say.

Finally we must recognize that there are social pressures, peer-group pressures, alternative needs, against which advertising can do nothing, certainly in the short term. and to persuade ourselves otherwise would be like putting a bandaid on a headache.

\section{REFERENCES}

Advertising Association (1988). Public Attitudes to Advertising, London: NTC Publications Ltd.

Broadbent, S. (1980). Market Researchers Look at Advertising. Amsterdam: ESOMAR.

Fishbein, M. (1971). Some comments on the use of models in advertising research. In Translating Advanced Advertising Theories into Research Reality, pp. 297-318. Amsterdam: ESOMAR.

Joyce, T. (1967). What do we know about how advertising works? In The Market Researcher Looks At The Way Advertising Works, vol. 2. pp. 90-127. Amsterdam: ESOMAR.

Joyce. T. (1971). Further thoughts on advertising research. In Translating Advanced Advertising Theories into Research Reality, pp. 275-293. Amsterdam: ESOMAR.

McLuhan, M. (1964). Understanding Media or The Extensions of Man. Ncw York (1965): McGraw-Hill Paperback. London (1967): Sphere Paperback.

Ogilvy, D. (1963). Confessions of an Advertising Man. New York: Atheneum.

Ogilvy, D. (1978). Blood, Brains and Beer. New York: Atheneum. 